\title{
A Qualitative Study to Identify Skills and Competency Required for Hospital Managers
}

\author{
Omid Barati ${ }^{1,2}$, Ahmad Sadeghi ${ }^{2,3}$, Mohammad Khammarnia ${ }^{4}$, Elham Siavashi ${ }^{2,3}$, Gholamreza Oskrochi ${ }^{5}$
}

${ }^{1}$ Ph.D. of Health Care Management, Assistant Professor, Department of Health Care Management, School of Management and Information Sciences, Shiraz University of Medical Sciences, Shiraz, Iran

${ }^{2}$ Health Human Resource Research Center, School of Management and Medical Information, Shiraz University of Medical Sciences, Shiraz, Iran

${ }^{3}$ Ph.D. Candidate of Health Care Management, Department of Health Care management, School of Management and Information Sciences, Shiraz University of Medical Sciences, Shiraz, Iran

${ }^{4}$ Ph.D. of Health Care Management, Assistant Professor, Department of Public Health, Zahedan University of Medical Sciences, Zahedan, Iran

${ }^{5}$ Full Professor. American University of the Middle East, College of Engineering and Technology, Kuwait

\section{Type of article: Original}

\begin{abstract}
Introduction: Hospital managers aim to improve the efficiency and effectiveness of their institutions through leadership and guidance of medical personnel. Fulfilling these objectives requires a holistic approach to both the management of people and institutional prioritization. The aim of this study was to identify the skills and competencies that hospital managers must demonstrate in order to achieve their objectives.

Methods: In 2015, a regional, multi-center qualitative study was undertaken in Shiraz, Iran. Interviews and focus group discussions were conducted with university hospital managers, senior managers, faculty members, and post-graduate students, and the results were analyzed using the content analysis method by MAXQDA software.

Results: Eight key skill themes (communication, experience, appreciation of institution logistics/infrastructure, management skills, motivation, systematic problem solving, ethics, and financial/legal awareness) were identified among the hospital managers. The common challenges that face hospital institutions include problems with hierarchical and organizational structure, excessive rules and regulations, lack of resources, poor post-graduate education, and overall management. Recurring themes with respect to how these could be addressed included changing the culture and belief structure of the hospital, restructuring the organizational hierarchy, and empowering the people.

Conclusion: In our cohort, practical skills, such as communication and experience, were considered more important than theoretical skills for the effective management and administration of hospitals. Therefore, we suggest that practical, skill-based training should be emphasized for students of these disciplines so they will be better suited to deal with real world challenges. Further organizational improvements also can be attained by the active and constructive involvement of senior university managers.
\end{abstract}

Keywords: Skill, Capabilities, Hospital manager, Hospital, Challenges

\section{Introduction}

Healthcare managers have a legal and moral duty to ensure that high quality patient care is delivered with a constant drive for the further improvement of the care $(1,2)$. The effectiveness of managers in this setting is critical to ensuring that organizations, including hospitals, perform optimally. On an organizational level, effective management systems and behaviors (traits) affect organizational outcomes greatly (3), while, on an individual level, experience (time spent on the job) has been found to influence clinical safety and outcomes as well as process performance (1). Appropriate managerial skills also positively affect employees' outcomes, resulting in the

\section{Corresponding author:}

Assistant Professor Dr. Mohammad Khammarnia, Department of Public Health, Zahedan University of Medical Sciences, Zahedan, Iran. Tel: +98.7132340774, Fax:+98.7132340039, Email: m_khammar1985@yahoo.com Received: January 18, 2016, Accepted: April 29, 2016, Published: June 2016 iThenticate screening: April 29, 2016, English editing: May 17, 2016, Quality control: June 03, 2016 (C) 2016 The Authors. This is an open access article under the terms of the Creative Commons Attribution-NonCommercialNoDerivs License, which permits use and distribution in any medium, provided the original work is properly cited, the use is non-commercial and no modifications or adaptations are made. 
improvement of effectiveness $(4,5)$, quantity, and quality $(6,7)$. Therefore, it is not surprising that there is an urgent need, especially in developing countries, to develop and provide different management modalities to enable hospitals to improve outcomes and drive healthcare provisions forward (8). Previous work has demonstrated that healthcare managers often are under-skilled and under-prepared with respect to the gravity of their role. Lack of appreciation of the organizational hierarchy and internal politics, inability to effectively exercise authority or confront others about mistakes (9), and a general lack of professional (human, technical, computational) (4) and communication (10) skills all contribute to managers' inability to effectively perform their function. Organizational level challenges also contribute to the difficulties that healthcare managers may face; these often include rising costs and the pressure to maintain or improve the level of patient care provided, often without extra resources being available (11); they also can include institutional reforms that alter the dynamics of the organization (12), such as the electronic health system currently is running in Iranian hospitals (13). Despite the recent focus on the consolidation of health systems, few studies have reported large-scale efforts to improve hospital management in low-income countries, which is a central component of improving the delivery of health care (14). Therefore, the aim of this study was to identify the challenges that hospital managers face and the skills they must use to overcome these challenges in Shiraz, Iran. Shiraz University of Medical Sciences (SUMS) is one of the major medical centers in Iran, and the top managers of SUMS have paid noticeable attention to hospital management positions, and SUMS is one of the hospital manager education centers that educate and graduate hospital management experts every year. Ultimately, the goal was to provide useful information to policy makers and managers to aid in the recruitment, training, and deployment of capable and effective hospital managers in the future.

\section{Material and methods}

From June 2014 through July 2015, SUMS was involved in a prospective, multi-center, qualitative study that utilized content analysis. Since public hospitals are directly under the supervision of SUMS, the managers of these hospitals were more likely to participate in the study, so the managers of public hospital were included in the study. The managers of public hospitals (thirteen hospitals, top managers of SUMS, faculty member of health care management, and Ph.D. students were included in the study. Purposive sampling (15) was used to select 24 subjects from the directors, faculty members, graduates of healthcare management, and managers of the university. The sample size was determined via the data saturation principle, in keeping with methods used in other qualitative studies. Sampling was considered complete when no additional new data were obtained via content analysis. Sources for content data included focus groups and individual interviews. The inclusion criteria included prior experience working in a hospital environment, familiarity with hospital management, ability to communicate effectively, and being able to commit to the time requirements of the study. An interview guideline was prepared that contained three general questions to clarify the objectives of the study. In order to assess the validity and reliability of the significance of the questions, two interviews with people who were not among the participants were conducted as a pilot study. According to the feedback received from the pilot study, the necessary modifications were made.

The interviews generally lasted between 20 and 40 minutes based on the availability and the participation of each subject. Each interview started with an open question ("What do you say about the status of hospital management post?") in order to give a relaxed and informal environment in which to conduct the questioning. The topics of the questioning were focused on hospital management challenges, strategies for solving the challenges, and the skills and abilities required by managers. The interviews were recorded with the consent of the participants, and the recordings were transcribed line by line immediately after each session to determine data saturation time and to increase accuracy. The aim of the second part of the study was to elucidate the student's perspective, and it consisted of a two-hour focus group that involved six graduate students in health management who had previous work experience in management and who were selected via purposive sampling. Written consent was obtained from all of the participants to record the proceedings of the focus group. Other members of the focus group included the chairman (research team member) and a person whose responsibility was to record accurately the comments and non-verbal reactions of the subjects. Following an introductory briefing in which the participants were introduced to the conveners and the principles and methods of the focus group were explained (including strict confidentiality), the participants were asked questions by the conveners, and debate was generated. Following the meeting, the recording was transcribed and analyzed immediately. Interview and focus group materials were studied several times to obtain an overall impression of their contents. Then, content analysis with coding was performed, and 385 codes were obtained initially, and they were merged and classified based on their similarities. This process continued throughout the duration of the study. Data integrity was maximized through continuous iterative analysis of the gathered information by multiple study conveners and external peer reviewers. To achieve data 
trustworthiness and rigor, their credibility was ensured by using peer check (check data by other researchers) and member check (check data by other participants) and continuous data analysis (transcribing interviews on paper and reviewing them to develop the main themes). In addition, thick descriptions of the findings (dense, deep, detailed accounts" of a phenomenon of inquiry with particular consideration of the context(s) in which it occurs) were performed for conformability. Qualitative content analysis is a specialized technique in processing qualitative data to determine the presence of certain words and concepts, and this technique was used to process the data throughout the study. After becoming familiar with the scope and diversity of the content, the researchers adjusted the thematic framework accordingly to identify key concepts and issues. Then, the data from individual and group interviews were reviewed and annotated based on the thematic framework that was obtained and arranged according to the right thematic source. By comparing the relationships, concepts, contradictions and ideas, desired themes were extracted from the findings by two researchers who had no conflict of interest with the subject or relevant institutions. Approval for this study was obtained from the SUMS Ethics Committee.

\section{Results}

Twenty-four subjects were interviewed during the study, 22 of whom (92\%) were males, and the average time of interviews was 38 minutes. The mean age of the participants was 48 years. Seven themes and 24 sub-themes in relation to hospital manager skills and capabilities were identified (Table 1) from interviews (hospital managers [n $=$ 10], university administrators $[n=5]$, healthcare management faculty $[n=3]$ and health management students focus group discussions $[\mathrm{n}=6])$. An additional five themes and 21 sub-themes were identified with respect to the challenges that hospital managers face (Table 2).

Table 1. Themes and sub-themes outlined in relation to the skills and capabilities required by hospital managers

\begin{tabular}{|l|l|}
\hline Theme & Sub-theme \\
\hline $\begin{array}{l}\text { Interaction and } \\
\text { communication }\end{array}$ & $\begin{array}{l}\text { Internal communication, External communication, Ability to work with employees, } \\
\text { Understanding organizational behavior and mutual understanding of behaviors, } \\
\text { Motivating staff, Coordination skill }\end{array}$ \\
\hline Work experience & Having managerial experience, Having work experience in hospital settings \\
\hline $\begin{array}{l}\text { Knowledge of } \\
\text { management }\end{array}$ & $\begin{array}{l}\text { Understanding management science, Up-to-date knowledge of management science, } \\
\text { Familiarity with the tasks and functions of management roles }\end{array}$ \\
\hline $\begin{array}{l}\text { Understanding hospital } \\
\text { infrastructure }\end{array}$ & $\begin{array}{l}\text { Understanding institution processes, Understanding institution structure and } \\
\text { organization, Awareness of medical equipment and functions, Familiarity with } \\
\text { concepts and terminology of Medical Sciences }\end{array}$ \\
\hline $\begin{array}{l}\text { Personality and ethical } \\
\text { characteristics }\end{array}$ & $\begin{array}{l}\text { Displays the personality and prestige of management (e.g., approachability, have } \\
\text { integrity, be authoritative, be ambitious), Ethical, Trustworthy, Prioritizing } \\
\text { organizational interests on individual interests }\end{array}$ \\
\hline $\begin{array}{l}\text { Systematic thinking and } \\
\text { problem solving }\end{array}$ & $\begin{array}{l}\text { Offers strategic inputs to the organization, Analysis and problem solving, Conceptual } \\
\text { skills }\end{array}$ \\
\hline Motivation and interest & Motivated and interested to manage, Interest in working in a hospital setting \\
\hline
\end{tabular}

Table 2. Themes and sub-themes outlined in relation to the challenges facing hospital management

\begin{tabular}{|l|l|}
\hline Theme & Sub-theme \\
\hline $\begin{array}{l}\text { University } \\
\text { structure }\end{array}$ & $\begin{array}{l}\text { Multiple and non-uniform monitoring and decision making centers, Instability of } \\
\text { management, Lack of sufficient authority, Disproportion of authority and responsibility, Lack } \\
\text { of transparency in roles and tasks of managers, Poor teamwork, Hospital's age, Working with } \\
\text { experienced human resources }\end{array}$ \\
\hline $\begin{array}{l}\text { Rules and } \\
\text { guidelines }\end{array}$ & $\begin{array}{l}\text { Lack of transparency in organizational rules and processes, Lack of transparency in hospital } \\
\text { indicators of assessment, Rapid changes in rules and Guidelines }\end{array}$ \\
\hline $\begin{array}{l}\text { Resources and } \\
\text { facilities }\end{array}$ & $\begin{array}{l}\text { Lack of financial resources, Lack of human resources, Poor management of resources, } \\
\text { Employees' resistance to change }\end{array}$ \\
\hline Training courses & $\begin{array}{l}\text { Inadequacy of training courses, Insufficient training in educational period, Gap between } \\
\text { teaching and field work, Pressures from educational departments }\end{array}$ \\
\hline $\begin{array}{l}\text { Macro and } \\
\text { superior policies }\end{array}$ & $\begin{array}{l}\text { Multiple national plans and policies (health reform plan, the family physician), Redundant } \\
\text { bureaucracy }\end{array}$ \\
\hline
\end{tabular}




\subsection{The skills and capabilities required by hospital managers}

Table 1 show the skills and capabilities required by hospital managers.

\subsubsection{Interaction and communication}

Proficiency in communication skills was found to be a recurring theme both in the focus group and interviews, and it was considered to be a fundamental requirement and a basic aspect of success in a management position. Some comments that were made included: "I think the most important key to success is related to good public relations" participant no. 2 (P2); "In my opinion, communication skills are very important, but the majority of our managers do not have them" (P13, P3).

\subsubsection{Work experience}

Work experience is one of the most important skills for managers, as was identified by all participants and has been suggested as one of the requirements for appointing people to hospital management posts and working in hospital administration. Some comments were as follows: "The most important requirement for a hospital manager is work experience in hospital administration for 5 to 10 years" (P3); "If the manager does not have enough experience, her/his decision can damage the health infrastructure" (P6). Most participants suggested a linear progression with respect to promotion of those who serve in health management posts. The belief was that, in order to effectively manage, higher management should have been involved in and undertaken roles in lower level posts first. This sentiment was echoed even among the healthcare management students.

\subsubsection{Knowledge of management}

A good theoretical knowledge base was identified as a significant theme throughout. Many mentioned that a hospital manager should be aware of scientific issues and have enough knowledge in all aspects of the institution to be able to provide effective management input. In this regard, one of the participants commented: "I think one of the most important factors is having sufficient knowledge. This means that, if a person were transferred to the Human Resources sector, he or she must know what is recruiter ruling and how it issued; if he/she went to the administrative-financial department and gave her/his financial balance, he/she could understand whether the hospital has a profit or a loss; if he/she were showed an outsourcing contract in contracts unit, understand what the framework of this contract is and it is in compliance with the principles of contract or not" (P11).

\subsubsection{Understanding the hospital infrastructure}

This theme encompasses understanding of the hierarchy, administrative and clinical processes, medical equipment, concepts, and terminology. Most participants felt that, although in-depth understanding of all the stated concepts was not mandatory, a passing, but workable, understanding was essential. For instance, one of the participants commented: "A hospital manager should have experience in all parts of the hospital, the hospital's processes, and its equipment to be able to manage the system properly, i.e., how this hospital performs, what capabilities it has, who are the users, and what its limitations are (P12).

\subsubsection{Personality and ethical characteristics}

Personality and ethical characteristics were two concepts that most participants noted as the requirements of hospital manager. "A manager should be a role model in terms of ethics, behavior, and personality" (P3).

Some managers believed that if the manager wants to modify or change the organization, initially he/she should start with herself/himself and then become a role model for others.

\subsubsection{Systematic thinking and problem solving}

Having a long-term and strategic vision with the ability to analyze the organization and solve problems also was a recurring theme among the participants. Having strategic thinking and a managerial perspective had priority over other skills in the hospital. Currently, most of our managers have a sectional perspective, so they get accustomed to routine life. Some of our managers are accustomed to routine life, and they think that, if they ignore a problem, the problem is solved. These individuals do not have either a macro or an analytical perspective" (P11).

\subsubsection{Motivation and interest}

Some of participants stated that those who wish to be hospital managers should have the motivation and interest to work in hospital settings. In this regard, one of the participants believed: "The hospital has a specific environment, and working in this environment requires a specific morale. If he/she does not have interest, he/she cannot become successful in this setting" (P8); "One of the main conditions for getting a manager's position is the person should be motivated and be able to motivate other staff members. An unmotivated manager can discourage the whole system" (P10). Students and lecturers also believed interest and motivation should be developed in individuals during their formative training. Talented, interested, and motivated individuals should be identified and introduced to work in the hospital and hospital management posts in the later stages.

\subsection{The challenges facing hospital management}

Table 2 shows the challenges that face hospital managers. 


\subsubsection{Weak organizational structure}

Most hospital management challenges are related to structural issues. Most hospital managers stated that there are numerous centers of decision-making and monitoring; "There are many centers of decision-making for the hospitals in the University" (P7). Also, almost all of the managers believed that they did not have the necessary executive authority in their role. Indeed, there was no congruence between the authority and responsibility with accountability. "Currently, most managers are not managers or they do not use their management skills; in fact, they only do the orders that issued by top managers to them and they have not any authority" (P7). Most hospital managers, staff managers, and teachers believed there is no coherence and coordination and they could not work as a team because the manager, chief and matron are selected by various external authorities. For example, one of the participants expressed: "This is fundamentally a wrong approach that treatment deputy chooses hospital chief; development deputy chooses managers; and nursing office chooses matron. In many cases these individuals do not coordinate with each other. These three should be a collaborative team for a hospital to run smoothly "(P11).

\subsubsection{Rules and guidelines}

Redundant rules and lack of transparency in rules and guidelines were considered a challenge for hospital managers; "The bureaucracy and some rules do not let the manager extend even one of its departments" (P10); "The challenges facing hospital managers are multiplicity of rules and regulations and frequent changes in the rules. For example, in recent years, you can delegate a department to the private sector. But, next year, you will hear about a conflicting rule" (P2).

3.2.3. Resources and facilities

Participants considered the lack of human and financial resources to be one of the hospital's major challenges. In this regard, one of the senior managers expressed: "Currently, hospital managers actually involve in executive and operational matters in hospital. A manager involves in the field of human resources and its deficiency" (P17). Some participants also expressed other shortcomings: "Hospitals have serious problems in the lack of nursing staff" (P5); "Managers have high workload with a little time" (P6).

\subsubsection{Training courses}

Pressure from educational departments also was expressed frequently: "In teaching hospitals, educational departments can establish or eliminate a department through their power" (P11). In this regard, many post-graduate students expressed that the quality of training courses should be improved by reducing the number of students: "A set of basic criteria should be established to accept the students to this course. First, it must be limited in order to provide training with higher quality for our students" (P23); "The topics which are training are not in accordance with their needs in future" (P21).

\subsubsection{Macro and superior policies}

Communicating and implementing some macro projects and programs in a short time-frame is a challenge for managers. "For example, since the beginning of health reform plan, perhaps 15-16 memos have been sent, some of which contradicted each other; this will confuse the hospital manager regarding service delivery" (P11). Another participant said: "New rules come frequently, and managers get involved with new challenges every day. For example, consider last year, we had: i) health reform plan, ii) performance-based payment, ii) relative values book" (P9).

\section{Discussion}

This study identified hospital managers' skills and challenges for delivering better services within our organization. There is now a strong body of literature establishing that senior managers in hospitals and acute care health services have a responsibility for ensuring the success of quality and safety programs (18-20). It is therefore essential for managers to improve their skills and capabilities. Hamidi et al. found that the professional skills level (human, conceptual, technical and design skills) was moderate in $56 \%$ of the managers of health centers in Iran. They also found that, as the level of a managers' professional skills increased, there was a proportional decrease in employees' job stress; therefore, training and developing managerial skills in supervisors and managers of health centres can reduce job stress and enhance effective performance (4). Kebede et al. stated that the establishment of hospital manager training in order to better equip them with management skills may promote scalable improvements in health facility functioning (14). As senior health care managers play an important role in the design and operationalization of quality improvement programs, they can offer a unique perspective on how to improve areas of practice with which healthcare organizations are often struggling to improve (21). This study showed that people skills were important for hospital managers. Manager's people skills increase the attraction and acceptance of the manager by subordinates, improve the friendliness of the work situation, and decrease stress $(5,6,22,23)$. Khadka et al. stressed the importance of communication skills and information management in hospital managers. They suggested that leadership skills and communication are the most important competitive factors known among 
hospital managers (24). Pillay et al. stated that the human resource management is the most important management skill in health services (25). Tabibi et al. found a relationship between the underlying communication skills of managers and staff motivation (26). Nevertheless, post-graduate students who participated in the study mentioned that they had not any formal training in communication skills, nor is it in their syllabus. Therefore, we suggest that the inclusion of this critical theme in the health-management curriculum needs to be considered and implemented in order to ensure that future students are better equipped. Job experiences and management knowledge also were identified as important for effective management in hospitals. Gerontol et al. found that hospital management students who spent more time in their future institution were more aware of the requirements of the institution and more in touch with the requirements of the patients who utilized those hospitals. However, Khadka et al., in a study in Nepal, concluded that knowledge management is less important (24), although this study was conducted in private and public hospitals with 59\% of managers surveyed having not had any management training. Understanding the processes of a hospital was another manager's required skill. Filerman, along these lines, stated that knowledge of hospital process is a requirement for a hospital manager (27). Hospitals are some of the most important and most complex institutions in a healthcare setting. Therefore, managers must be able to think systematically with respect to problem solving. Systematic thinking is a conceptual framework for problem solving that works by problem analysis, prediction of implementation issues, and enhancing organizational understanding of the issues. The relationship between systems thinking and improved employee performance has been proven. Terzic-Supic et al. found that training for strategic planning and management enhanced the strategic decisionmaking of hospital management teams (28).

In this study, financial skills were determined as an important skill for hospital managers. Whetsell et al. stated that to fully understand health care finance and be effective in reducing costs, hospital managers need to understand the history and evolution of the payment system and how they have influenced both cost measurement and cost control efforts (29). Having motivation and interest for working in the hospital was considered as one of the requirements mentioned in some interviews for hospital manager. Authorities should be aware that having incentives for working in a hospital is one of the main criteria for hospital management. Identifying the hospital manager's challenges was another purpose of the study. Our results showed that organizational and structural problems, such as the incompatibility between the hospital authority and responsibility, were the most important challenges in hospital management posts. To be able to effectively perform their duties, hospital managers must have sufficient authority, in proportion to their responsibilities, a fact that has not been realized in either public or private Iranian hospitals since 2002. Lack of transparency rules and duties and role of managers also were expressed as challenges for hospital management. McInnes et al. found that culture change starts with leaders and is one of the main issues that managers have faced in hospitals (21). Therefore, it is suggested that high-level meetings should be scheduled between the Ministry of Health and university heads at early stages in order to gain leadership support in deploying change. The macroeconomic policies of the Iran Health Ministry also were considered a challenge. Sometimes, rules and guidelines which dictated to hospitals create challenges for the hospitals. Shwekerela et al. found that hospital reforms in Tanzania lead to many challenges for hospital management in level II public hospitals (12). Therefore, the rules should be according to hospital process and procedures and direct them to better performance. Lack of training was another of the major challenges in the hospital management position. Hospital managers frequently stated that education should be based on their needs, and this should be addressed so that the essential skills are taught in a formal manner. Terzic-Supic et al. stated that the positive effects of the formal training program justify additional investment in future education and training (28). Moreover, continuing education and training have become parts of the ongoing processes of organizational learning (30) and are essential tools for managers to improve their management skills and to learn new skills $(31,32)$. The lack of studies on hospital manager skills and challenges was one of the limitations we found, as it prevented direct comparison. Therefore, in this study, we compared our themes with those in a similar setting. Busy work-life style of the participants to perform the interview was another limitation of this study.

\section{Conclusions}

Interaction and communication, work experience, knowledge management, rrecognition of hospital processes, motivation, personality characteristics and moral skills, and management are requirements for hospital managers. Nevertheless, there are very few formal training or educational opportunities in order to nurture and develop these skills. Senior decision makers should select hospital managers based on these criteria. Extensive and continuous communication with other hospitals, academic centers and universities, supporting senior managers of hospital managers, increase of the hospital manager's authority, clarification of the duties and roles of the hospital manager, 
and creating and fostering a culture of manager training in hospitals and universities are recommended to promote hospital managers' skills. Also, it is recommended to conduct a similar study for private hospitals.

\section{Acknowledgments:}

The authors thank the Research Vice-Chancellor of Shiraz University of Medical Sciences for financially supporting the research (Contract No. 7810-68-01-93). Also, they thank the managers of SUMS and the School of Management and Medical Information.

\section{Conflict of Interest:}

There is no conflict of interest to be declared.

\section{Authors' contributions:}

All authors contributed to this project and article equally. All authors read and approved the final manuscript.

\section{References:}

1) Parand A, Dopson S, Renz A, Vincent C. The role of hospital managers in quality and patient safety: a systematic review. BMJ open. 2014; 4(9): 005055. doi: 10.1136/bmjopen-2014-005055. PMID: 25192876, PMCID: PMC4158193.

2) Berwick D. Will is the way to win the patient safety war. Health Serv J. 2007; 117(6044): 18-9. PMID: 17380934.

3) Aij KH, Aernoudts RL, Joosten G. Manager traits and quality-of-care performance in hospitals. Leadersh Health Serv. 2015; 28(3): 200-15. doi: 10.1108/LHS-07-2014-0053. PMID: 26083635.

4) Hamidi Y, Eivazi Z. The relationships among employees' job stress, job satisfaction, and the organizational performance of Hamadan urban health centers. Social Behavior and Personality. 2010; 38(7): 963-8. doi: 10.2224/sbp.2010.38.7.963.

5) Griffin ML. Gender and stress a comparative assessment of sources of stress among correctional officers. Journal of Contemporary Criminal Justice. 2006; 22(1): 5-25. doi: 10.1177/1043986205285054.

6) Salami A, Ojokuku R, Ilesanmi O. Impact of job stress on managers' performance. European Journal of Scientific Research. 2010; 45(2): 249-60.

7) Supic ZT, Bjegovic V, Marinkovic J, Milicevic MS, Vasic V. Hospital management training and improvement in managerial skills: Serbian experience. Health policy. 2010; 96(1): 80-9. doi: 10.1016/j.healthpol.2010.01.002. PMID: 20116126.

8) Chadwell I, Bhitrakoti R, Khadka R. Measuring Management Training Needs of Hospital Managers in Nepal. JNMA J Nepal Med Assoc. 2012; 52(186): 52-60. PMID: 23478730.

9) Howard DM. How Health Management Leaders Evaluate the Interpersonal Skills of US Business and Health Management-Trained Professionals. Medical Research Archives. 2015(3).

10) Hamidi Y, Barati M. Communication Skills of Heads of Departments: Verbal, Listening, and Feedback Skills. J Res Health Sci. 2011; 11(2): 91-6. PMID: 22911958.

11) Ghorbani AA, Hesamzadeh A, Khademloo M, Khalili S, Hesamzadeh S, Berger V. Public and private hospital nurses' perceptions of the ethical climate in their work settings, Sari city, 2011. Nurs Midwifery Stud. 2014; 3(1): 12867. PMID: 25414890, PMCID: PMC4228523.

12) Shwekerela B. The effects of hospital reforms on the management of public hospitals in Tanzania: Challenges and lessons learnt. World Hosp Health Serv. 2014; 50(4): 23-6. PMID: 25985557.

13) Bastani P, Abolhasani N, Shaarbafchizadeh N. Electronic Health in Perspective of Healthcare Managers: A Qualitative Study in South of Iran. Iran J Public Health. 2014; 43(6): 809-20. PMID: 26110152, PMCID: PMC4475600.

14) Kebede S, Mantopoulos J, Ramanadhan S, Cherlin E, Gebeyehu M, Lawson R, et al. Educating leaders in hospital management: A pre-post study in Ethiopian hospitals. Glob Public Health. 2012; 7(2): 164-74. doi: 10.1080/17441692.2010.542171. PMID: 21259143.

15) Ritchie J, Lewis J, Nicholls CM, Ormston R. Qualitative research practice: A guide for social science students and researchers: Sage; 2013.

16) Forman J, Damschroder L. Qualitative content analysis. Empirical Research for Bioethics: A Primer. Oxford, UK: Elsevier Publishing. 2008.

17) Beigzadeh A, Okhovati M, Mehrolhasani M, Shokoohi M, Bazrafshan A. Challenges of the bachelor program of health services management: a qualitative study. Journal of Health Administration (JHA). 2014; 17(55): 29-42. 
18) Braithwaite J, Westbrook MT, Robinson M, Michael S, Pirone C, Robinson P. Improving patient safety: the comparative views of patient-safety specialists, workforce staff and managers. BMJ Qual Saf. 2011; 20(5): 424-31. doi: 10.1136/bmjqs.2010.047605. PMID: 21242528.

19) Leggat SG, Balding C, Anderson J. Empowering health-care managers in Australia: an action learning approach. Health Serv Manage Res. 2011; 24(4): 196-202. doi: 10.1258/hsmr.2011.011012. PMID: 22040947.

20) Leggat S, Bartram T, Stanton P. Exploring the lack of progress in improving patient safety in Australian hospitals. Health Serv Manage Res. 2008; 21(1): 32-9. doi: 10.1258/hsmr.2007.007012. PMID: 18275663.

21) McInnes E, Phillips R, Middleton S, Gould D. A qualitative study of senior hospital managers' views on current and innovative strategies to improve hand hygiene. BMC Infect Dis. 2014; 14(1): 611. doi: 10.1186/s12879-014-0611-3. PMID: 25407783, PMCID: PMC4237732.

22) Erkutlu HV, Chafra J. Relationship between leadership power bases and job stress of subordinates: example from boutique hotels. Management Research News. 2006; 29(5): 285-97. doi: 10.1108/01409170610674419.

23) AbuAlRub RF, Al-Zaru IM. Job stress, recognition, job performance and intention to stay at work among Jordanian hospital nurses. J Nurs Manag. 2008; 16(3): 227-36. doi: 10.1111/j.1365-2834.2007.00810. PMID: 18324981.

24) Khadka DK, Gurung M, Chaulagain N. Managerial competencies-A survey of hospital managers' working in Kathmandu valley, Nepal. Journal of Hospital Administration. 2014; 3(1): 62. doi: 10.5430/jha.v3n1p62.

25) Pillay R. The skills gap in hospital management: a comparative analysis of hospital managers in the public and private sectors in South Africa. Health Serv Manage Res. 2010; 23(1): 30-6. doi: 10.1258/hsmr.2009.009015. PMID: 20150608.

26) Tabibi SJ, Nasiripoor A, Zahiri Abyaneh Z. Relationship Between Managers Communication Skill and Staff Motivation in Modarres Hospital of Tehran. Hospital Journal. 2013; 12(2): 73-80.

27) Filerman GL. Closing the management competence gap. Hum Resour Health. 2003; 1(7): 1-3. doi: 10.1186/1478-4491-1-7. PMCID: PMC270080.

28) Terzic-Supic Z, Bjegovic-Mikanovic V, Vukovic D, Santric-Milicevic M, Marinkovic J, Vasic V, et al. Training hospital managers for strategic planning and management: a prospective study. BMC Med Educ. 2015; 15(1): 25. doi: 10.1186/s12909-015-0310-9. PMID: 25889166, PMCID: PMC4355452.

29) Whetsell GW. The history and evolution of hospital payment systems: how did we get here? Nurs Adm Q. 1999; 23(4): 1-15. PMID: 10711138.

30) Lingham T, Richley B, Rezania D. An evaluation system for training programs: a case study using a fourphase approach. Career development international. 2006; 11(4): 334-51. doi: $10.1108 / 13620430610672540$.

31) Davies S. Health services management education: why and what? J Health Organ Manag. 2006; 20(4): 32534. PMID: 16921816.

32) Gregory D, Baigelman W, Wilson IB. Hospital economics of the hospitalist. Health Serv Res. 2003; 38(3): 905-18. PMID: 12822918, PMCID: PMC1360922. 